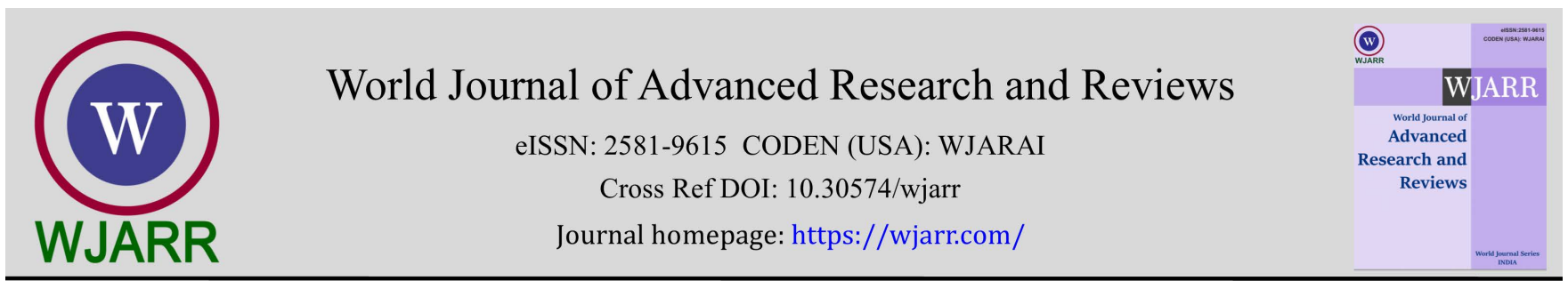

(RESEARCH ARTiClE)

\title{
Current insecticide resistance status in malaria vector populations from Dogbo district in South-western Republic of Benin, West Africa
}

\author{
Nazaire Aïzoun 1, ${ }^{*}$, Guévara Nonviho ${ }^{1}$, Frédéric Aïzoun ${ }^{2}$ and Faustin Assongba 3, 4 \\ ${ }^{1}$ Laboratory of Pluridisciplinary Researches of Technical Teaching (LaRPET), Normal High School of Technical Teaching \\ (ENSET) of Lokossa, National University of Sciences, Technologies, Engineering and Mathematics (UNSTIM) of Abomey, P. \\ O. Box 133 Lokossa Cotonou, Benin. \\ ${ }^{2}$ Unity of Researches in Biotechnology of Aninal Production and Health (URBPSA), Polytechnic School of Abomey-Calavi \\ (EPAC), University of Abomey-Calavi (UAC), Cotonou, Bénin. \\ ${ }^{3}$ Laboratory of Vegetal Biology and Traditional Pharmacopoeia (LaBVephaT), National High School of Applied \\ Biosciences and Biotechnologies (ENSBBA) of Dassa-Zoumè, National University of Sciences, Technologies, Engineering \\ and Mathematics (UNSTIM) of Abomey. \\ ${ }^{4}$ Laboratory of Applied Ecology (LEA), Faculty of Agronomic Sciences, University of Abomey-Calavi (UAC), Cotonou, \\ Bénin.
}

World Journal of Advanced Research and Reviews, 2022, 13(02), 225-231

Publication history: Received on 05 January 2022; revised on 05 February 2022; accepted on 07 February 2022

Article DOI: https://doi.org/10.30574/wjarr.2022.13.2.0135

\begin{abstract}
This study was aimed to investigate thecurrent insecticide resistance status in malaria vector mosquitoes from Dogbo district in South-western Benin, West Africa. Larvae and pupae of Anopheles gambiae s.l. populations were collected from the breeding sites from March to July 2020 during the first rainy season in Couffo department using the dipping method. WHO susceptibility tests were conducted on unfed female mosquitoes aged 2-5 days old. WHO bioassays were performed with impregnated papers of permethrin (0.75\%), deltamethrin (0.05\%), cyfluthrin (0.15\%), lambdacyhalothrin (0.05\%) and dichlorodiphenyltrichloroethane (DDT) (4\%). An. gambiaes.l. populations from Dogbo district were resistant to permethrin, deltamethrin, cyfluthrin, lambdacyhalothrin and DDT. There is cross-resistance to both pyrethroid and DDT insecticides. However, the physical barrier of Long Lasting Insecticidal Nets (LLINs) which are regularly distributed free by Beninese National Malaria Control Programme throughout the entire country to increase coverage of LLINs is still important despite the insecticide resistance observed.
\end{abstract}

Key words: Anopheles gambiae; Resistance; Pyrethroids; DDT; Republic of Benin

\section{Introduction}

The intense use of DDT in agriculturalsettings and during the WHO malaria eradication programme in the 1950s and 1960s were suspected to be the main factors selecting for pyrethroids and DDT resistancein An. gambiae populations [1]. Pyrethroids are the only option for net treatment due to their relative safety for humans at low dosage, excitorepellent properties, rapid rate of knock-down andkilling effects [2]. However, widespread reports of pyrethroid resistancein An. gambiae in West and East Africa [3-4] and its cross-resistance with DDT are major challenges to its adoption for vector control purposes. Resistance to the insecticide DDT in the mosquito vectors of malaria has severely hampered efforts to control this disease and has contributed to the increase in prevalence of malaria cases. Over $90 \%$ of the 300-500 million annual cases of malaria occur in Africa, where the major vector is Anopheles gambiae s.l. [5].

\footnotetext{
*Corresponding author: Nazaire Aïzoun

Laboratory of Pluridisciplinary Researches of Technical Teaching (LaRPET), Normal High School of Technical Teaching (ENSET) of Lokossa, National University of Sciences, Technologies, Engineering and Mathematics (UNSTIM) of Abomey, P. 0. Box 133 Lokossa Cotonou, Benin.
}

Copyright (C) 2022 Author(s) retain the copyright of this article. This article is published under the terms of the Creative Commons Attribution Liscense 4.0. 
In Benin as across Africa, malaria control relies heavily on vector control through the use of insecticide-treated nets (ITN) and indoor residual spraying (IRS). In West Africa, the main mechanism involved in pyrethroid-resistance in Anopheles gambiae is caused by target site insensitivity through a knockdown resistance ( $k d r)$-like mutation caused by a single point mutation (Leu-Phe) in the para-sodium channel gene [4]. Malaria vector resistance to insecticides in Benin is conferred by two main mechanisms: (1) alterations at site of action in the sodium channel, viz the $k d r$ mutations and (2) an increase of detoxification and/or metabolism through high levels of multi-function oxidases (MFOs), non-specific esterases (NSEs) [6-10].

Although it was shown by Ranson et al.[11], that a leucine phenylalanine substitution at position 1014 of the voltage gated sodium channel is associated with resistance to permethrin and DDT in many insect species, including Anopheles gambiae s.l from West Africa, another study has shown that target site mutation $(k d r)$ was not responsible for DDT and permethrin resistance in An. arabiensis populations, a major malaria vector in Nigeria. This study has likely suggested the involvement of metabolic resistance mechanisms in this resistance [12].

Beninese National Malaria Control Programme has recently implemented large-scale and free distribution of longlasting insecticidal nets (LLINs) throughout the entire country to increase coverage of LLINs. It is crucial that information on current status of An. gambiae s.l. resistance to pyrethroid being investigated. This will properly inform control programs of the most suitable insecticides to use and facilitate the design of appropriate resistance management strategies. In this study, we report the assessment of the susceptibility status, insecticide resistance levels in Anopheles gambiae s.l. to permethrin, deltamethrin, cyfluthrin, lambdacyhalothrin and DDT.

\section{Material and methods}

\subsection{Study area}

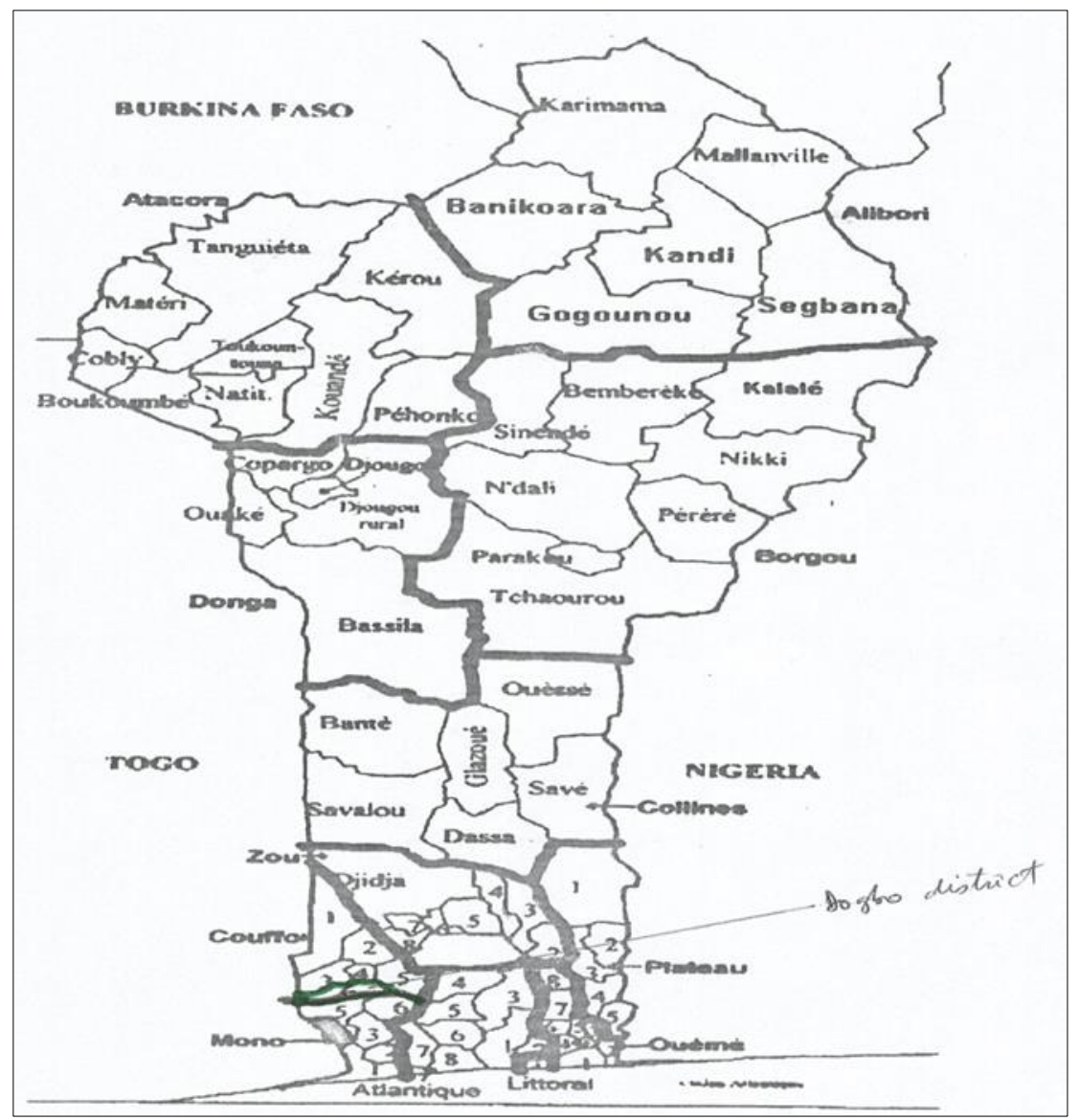

Figure 1 Map of Republic of Benin showing Dogbo district surveyed

The study area is located in Republic of Benin (West Africa) and includes the department of Couffo. Couffo department is located in the south-western Benin and the study was carried out more precisely in Dogbo district (Fig.1). The 
southern borders of this district are Lokossa and Bopa districts. The northern border is Djakotomey district. The eastern border is Lalo district and the western border of Dogbo district is Togo republic. Dogbo district covered $475 \mathrm{~km}^{2}$ and belongs to geographic region of ADJA.The choice of the study site took into account the economic activities of populations, their usual protection practices against mosquito bites, and peasant practices to control farming pests. We took these factors into account to study the current insecticide resistance status in Anopheles gambiae sensu lato populations from Dogbo district in South-western Republic of Benin. Couffo has a climate with four seasons, two rainy seasons (March to July and August to November) and two dry seasons (November to March and July to August). The temperature ranges from 25 to $30^{\circ} \mathrm{C}$ with the annual mean rainfall between 900 and $1100 \mathrm{~mm}$.

\subsection{Mosquito sampling}

An. gambiae s.l. populations were collected from March to July 2020 during the first rainy season in Dogbo district. Larvae and pupae were collected in this district within both padding and village using the dipping method on several breeding sites (brick pits, pools, marshes, streams, ditches, pits dug for plastering traditional huts, puddles of water, water pockets caused by the gutters). Then, they were kept in separated labeled bottles related to Dogbo district surveyed. Otherwise, larvae collected from multiple breeding sites were pooled together and then re-distributed evenly in development trays containing tap water. Larvae were provided access to powdered TetraFin $®$ fish food, and were reared to adults under insectary conditions of $25+/-2^{\circ} \mathrm{C}$ and 70 to $80 \%$ relative humidity at Laboratory of Applied Entomology and Vector Control of the Department of Sciences and Agricultural Techniques located in Dogbo district in south-western Benin. An. gambiae s.l. Kisumu, a reference susceptible strain was used as a control for the bioassay tests.

Susceptibility tests were done following WHO protocol on unfed females mosquitoes aged 2-5 days old reared from larval and pupal collections. All susceptibility tests were conducted in the Laboratory of Applied Entomology and Vector Control (LAEVC) at $25+/-2^{\circ} \mathrm{C}$ and 70 to $80 \%$ relative humidity.

\subsection{Testing insecticide susceptibility}

The principle of the WHO bioassay is to expose insectsto a given dose of insecticide for a given time to assess susceptibility or resistance. The standard WHO discriminating dosages are twice the experimentally derived $100 \%$ lethal concentration(LC100 value) of a reference susceptible strain (WHO, 1998). In this study, the insecticides tested were permethrin (0.75\%), deltamethrin (0.05\%), cyfluthrin (0.15\%), lambdacyhalothrin (0.05\%) and dichlorodiphenyltrichloroethane (DDT) (4\%). The choice of permethrin and deltamethrin was justified by their recent use on LLINs (OlysetNets for permethrin and Permanet 2.0 for deltamethrin) which were used by National Malaria Control Programme (NMCP) for implementation of large-scale and free distribution through the entire country to increase coverage. We used cyfluthrin and lambdacyhalothrin to assess cross-resistance between pyrethroid insecticides. DDT was tested because of its intensive use in the past as well as to assess cross-resistance to organochlorine and pyrethroid insecticides.

An aspirator was used to introduce 20 to 25 unfed female mosquitoes aged 2-5 days into five WHO holding tubes (four tests and one control) that contained untreated papers. They were then gently blown into the exposure tubes containing the insecticide impregnated papers. After one-hour exposure, mosquitoeswere transferred back into holding tubes and provided with cotton wool moistened with a $10 \%$ honey solution. The number of mosquitoes "knocked down" at 60 minutes and mortalities at 24 hours were recorded following the WHO protocol [13].

\subsection{Statistical analysis}

The resistance status of the used mosquito sample was determined according to the WHO criteria [14] as follows:

- $\quad$ Mortality rates between $98 \%-100 \%$ indicate full susceptibility.

- Mortality rates between 90\%-97\% indicate possible resistance.

- $\quad$ Mortality rates $<90 \%$, the population is considered resistant to the tested insecticides

Abbott's formula was not used in this study for the correction of mortality rates in the test-tubes because the mortality rates in all controls was always less than 5\% [15]. Analysis using Fisher's exact test and test of proportion was performed on the data sets gathered from the Dogbo district surveyed to compare each of tested insecticidesand to assess the resistance status. 


\section{Results}

\subsection{Determination of Knock down time (Kdt) and resistance ratio (RR)}

The resistance ratios (RR50) of the wild populations of Anopheles gambiae s.l. from Dogbo with regard to Anopheles gambiae s.l. Kisumu susceptible reference strain were 1.853, 2.220, 2.483, 2.600 and 3.484 respectively for DDT, permethrin, deltamethrin, cyfluthrin and lambdacyhalothrin. These resistance ratios (RR50) were all higher than 1 (Table 1).

The same remark was made with the resistance ratios (RR95). They were 1.677, 1.876, 2.027, 2.089 and 2.410 respectively for DDT, permethrin, deltamethrin, cyfluthrin and lambdacyhalothrinn. These results showed that the populations of Anopheles gambiae s.l. from Dogbo were resistant to these products (Table 1).

Table 1 Determination of Knock down times 50 (Kdt50), Knock down times 95 (Kdt95), resistance ratios 50 (RR50) and resistance ratios 95 (RR95)

\begin{tabular}{|l|l|c|c|c|c|}
\hline Populations & Insecticides & Kdt50 (min) & RR50 & Kdt95 (min) & RR95 \\
\hline \multirow{5}{*}{$\begin{array}{l}\text { Kisumu } \\
\text { (Control) }\end{array}$} & DDT & 43.313 & - & 54.024 & - \\
\cline { 2 - 6 } & Permethrin & 30.245 & - & 41.093 & - \\
\cline { 2 - 6 } & Deltamethrin & 24.689 & - & 35.103 & - \\
\cline { 2 - 6 } & Cyfluthrin & 22.790 & - & 33.246 & - \\
\cline { 2 - 6 } & Lambdacyhalothrin & 15.289 & - & 26.142 & - \\
\hline \multirow{5}{*}{ Dogbo } & DDT & 80.282 & 1.853 & 90.635 & 1.677 \\
\cline { 2 - 6 } & Permethrin & 67.156 & 2.220 & 77.123 & 1.876 \\
\cline { 2 - 6 } & Deltamethrin & 61.310 & 2.483 & 71.179 & 2.027 \\
\cline { 2 - 6 } & Cyfluthrin & 59.263 & 2.600 & 69.456 & 2.089 \\
\cline { 2 - 6 } & Lambdacyhalothrin & 53.278 & 3.484 & 63.012 & 2.410 \\
\hline
\end{tabular}

3.2. Mortality of An. gambiae s.l. populations from Dogbo district after one hour exposure to WHO impregnated papers with permethrin $(0.75 \%)$, deltamethrin $(0.05 \%)$, cyfluthrin $(0.15 \%)$, lambdacyhalothrin $(0.05 \%)$ and dichlorodiphenyltrichloroethane (DDT) (4\%)

Table 2 Determination of resistance status in Anopheles gambiae s.l. populations from Dogbo to permethrin, deltamethrin, cyfluthrin, lambdacyhalothrin and DDT

\begin{tabular}{|l|l|c|c|c|}
\hline Populations & Insecticides & Number tested & \% Mortality & Resistance status \\
\hline \multirow{5}{*}{$\begin{array}{l}\text { Kisumu } \\
\text { (Control) }\end{array}$} & DDT & 100 & 100 & $\mathrm{~S}$ \\
\cline { 2 - 5 } & Permethrin & 100 & 100 & $\mathrm{~S}$ \\
\cline { 2 - 5 } & Deltamethrin & 100 & 100 & $\mathrm{~S}$ \\
\cline { 2 - 5 } & Cyfluthrin & 100 & 100 & $\mathrm{~S}$ \\
\cline { 2 - 5 } & Lambdacyhalothrin & 100 & 100 & $\mathrm{~S}$ \\
\hline \multirow{5}{*}{ Dogbo } & DDT & 100 & 4 & $\mathrm{R}$ \\
\cline { 2 - 5 } & Permethrin & 100 & 34 & $\mathrm{R}$ \\
\cline { 2 - 5 } & Deltamethrin & 100 & 77 & $\mathrm{R}$ \\
\cline { 2 - 5 } & Cyfluthrin & 100 & 71 & $\mathrm{R}$ \\
\cline { 2 - 5 } & Lambdacyhalothrin & 100 & 84 & $\mathrm{R}$ \\
\hline
\end{tabular}

Kisumu strain (control) confirmed its susceptibility status as a reference strain. The 24 hours mortality recording shows that female Anopheles gambiae Kisumu which were exposed to WHO papers impregnated with permethrin (0.75\%), 
deltamethrin $(0.05 \%)$, cyfluthrin $(0.15 \%)$, lambdacyhalothrin $(0.05 \%)$ and dichlorodiphenyltrichloroethane (DDT) $(4 \%)$ were fully susceptible to these products. They were dead and none of them could fly after 24 hours mortality recording required by WHO (Table 2).

Regarding field collected female Anopheles gambiae s.l. populations from Dogbo district, they were resistant to permethrin (0.75\%), deltamethrin (0.05\%), cyfluthrin $\quad(0.15 \%)$, lambdacyhalothrin $\quad(0.05 \%) \quad$ and dichlorodiphenyltrichloroethane (DDT) (4\%) with the mortality rates of $34 \%, 77 \%, 71 \%, 84 \%$ and $4 \%$ respectively (Table 2).

\section{Discussion}

The management of insecticide resistance is a major issue, which must interest the different National Malaria Control Programmes. This management requires two kinds of information: sound knowledge of the mechanisms of resistance and a thorough resistance monitoring programme [9].The control of vector borne diseases uses different methods depending on physiological, behavioural and ecological features of the vector.

Female Anopheles gambiae s.l. populations from Dogbo have developed resistance to DDT, permethrin, deltamethrin, cyfluthrin and lambdacyhalothrin. The resistance to permethrin, deltamethrin, cyfluthrin and lambdacyhalothrin may be due to knock down effect which characterizes pyrethroids as there is a correlation between resistance level to pyrethroids and knock-down time [16-17]. Knock down effect is a characteristic of pyrethroids and it happens immediately after the insects are exposed to pyrethroids [18]. Therefore, if the time need for insects to be knocked down increases, it indicatesthat the insects may be resistant to the insecticide [19]. When insects are exposed to pyrethroids, they fall down but will not die immediately. For susceptible insects, they will eventually die. But for resistant insects, after they are knocked down for a while, they will recover and soon be able to fly again after the pyrethroids entering their bodies are detoxified by their metabolism [19]. Aïzoun et al.[10] have also already reported permethrin resistance in Anopheles gambiae s.l. populations from the location of Agbalilamè in the Sèmè district of Ouémé department in the south eastern Benin. It is worth mentioning that the locality of Agbalilame is crossed by the Nokoue Lake streams, which sweep and converge several environmental pollutants and pesticide residues from the neighbouring peri-urban cities and farms to the coastal locality of Agbalilame. It is also possible that several ranges of xenobiotics present in these water bodies around Agbalilame might have also contributed to the selection of this resistance in Anopheles gambiae. Deltamethrin, cyfluthrin and lambdacyhalothrin resistance was also reported in the country[20-22].

Female Anopheles gambiae s.l. populations from Dogbo were also resistant to DDT. The Knock down effect is not only a characteristic of pyrethroids. It is also a characteristic of DDT [17]. Resistance to DDT was widespread in the early 1970s because of its intensive use in public health and agriculture [23] and emerged after about 11 years of application [24]. Although DDT has been used in limited quantities for disease vector control during the past 3 decades, there have been recent reports of resistance in malaria vectors from African countries [25-26, 11, 27].

There is cross-resistance to both pyrethroid and organochlorine insecticides in the current study. This cross-resistance was also observed by other authors. In fact, according to Vulule et al. [3] and Chandre et al. [4], the pyrethroid resistance in An. gambiae in West and East Africa and its cross-resistance with DDT are major challenges to its adoption for vector control purposes.

\section{Conclusion}

There is cross-resistance to both pyrethroid and organochlorine insecticides. However, the physical barrier of LongLasting Insecticidal Nets (LLINs) which are regularly distributed free by Beninese National Malaria Control Programme throughout the entire country to increase coverage of LLINs is still important despite the insecticide resistance observed. Only the torn nets cannot protect people from malaria vector bites.

\section{Compliance with ethical standards}

\section{Acknowledgments}

The authors would like to thank people from locations surveyed who had helped us in mosquito collection. We would also like to thank KOUASSI Prisca for technical assistance in laboratory during the current study. 


\section{Disclosure of conflict of interest}

There is no conflict of interest among the authors.

\section{Statement of ethical approval}

The study follows proper ethical procedures.

\section{Statement of informed consent}

Informed consent was obtained from all individual participants included in the study.

\section{References}

[1] Akogbeto MC, Djouaka R, Noukpo H. L'utilisation des insecticides en agriculture au Bénin. Bull. Soc. Pathol. Exot. 2005; 98: 400-405.

[2] Zaim M, Aitio A, Nakashima N. Safety of pyrethroid-treated mosquito nets. Med. Vet. Entomol. 2000; 14:1-5.

[3] Vulule JM, Beach RF, Atieli FK, Mount DL, Roberts JM, Mwangu RW. Reduced Susceptibility of Anopheles gambiae to permethrin associated with the use of permethrin impregnated bednets and curtains in Kenya. Med. Vet. Entomol. 1994; 8: 71-5.

[4] Chandre F, Darriet F, Manga L, Akogbeto M, Faye 0, Mouchet J, Guillet P. Status of pyrethroid resistance in Anopheles gambiae sensu lato. Bull. World Health Organ. 1999; 77(3): 230-234.

[5] Ranson H, Jensen B, Wang X, Prapanthadara L, Hemingway J, Collins HF. Genetic mapping of two loci affecting DDT resistance in the malaria vector Anopheles gambiae. Insect Mol. Biol. 2000; 9(5): 499-507.

[6] Corbel V, N'Guessan R, Brengues C, Chandre F, Djogbenou L, Martin T, Akogbeto M, Hougard JM, Rowland M. Multiple insecticide resistance mechanisms in Anopheles gambiae and Culex quinquefasciatus from Benin, West Africa. Acta Trop. 2007; 101: 207-16.

[7] Djogbénou L, Pasteur N, Akogbéto M, Weill M, Chandre F. Insecticide resistance in the Anopheles gambiae complex in Benin: a nationwide survey. Med. Vet. Entomol. 2009; 69:160-164.

[8] Djègbé I, Boussari O, Sidick A, Martin T, Ranson H, Chandre F, Akogbéto M, Corbel V. Dynamics of insecticide resistance in malaria vectors in Benin: first evidence of the presence of L1014S kdr mutation in Anopheles gambiae from West Africa. Malar J. 2011; 10: 261.

[9] Aïzoun N, Ossè R, Azondekon R, Alia R, Oussou O, Gnanguenon V, Aïkpon R, Padonou GG, Akogbéto M. Comparison of the standard WHO susceptibility tests and the CDC bottle bioassay for the determination of insecticide susceptibility in malaria vectors and their correlation with biochemical and molecular biology assays in Benin, West Africa. Parasit Vector. 2013; 6: 147.

[10] Aïzoun N, Aïkpon R, Padonou GG, Oussou O, Oké-Agbo F, Gnanguenon V, Ossè R, Akogbéto M. Mixed function oxidases and esterases associated with permethrin, deltamethrin and bendiocarb resistance in Anopheles gambiae s.l. in the south-north transect Benin, West Africa. Parasit Vector. 2013; 6: 223.

[11] Ranson H, Jensen B, Vulule JM, Wang X, Hemingway J, Collins FH. Identification of a point mutation in the voltagegated sodium channel gene of Kenyan Anopheles gambiae associated with resistance to DDT and pyrethroids. Insect Mol. Biol. 2000; 9(5): 491-497.

[12] Oduola OA, Olojede BJ, Ashiegbu OC, Adeogun OA, Otubanjo AO, Awolola ST. High level of DDT resistance in the malaria mosquito: Anopheles gambiae from rural, semi-urban and urban communities in Nigeria. J Rural Trop. Public Health. 2010; 9: 114-120.

[13] WHO. Report of the WHO Informal Consultation. Tests procedures for insecticideresistance monitoring in malaria vectors, bioefficacy and persistence of insecticides on treated surfaces. Geneva: World Health Organization: Parasitic Diseases and Vector Control (PVC)/Communicable Disease Control, Prevention and Eradication (CPE). 1998:43.

[14] WHO. Procédures pour tester la résistance aux insecticides chez les moustiques vecteurs du paludisme Seconde édition (Seconde). Genève. 2017.

[15] Abbott WS. A method of computing the effectiveness of an insecticide. J. Am. Mosq. Control Assoc. 1987; 3(2): 302-303. 
[16] Akogbeto M, Yakoubou S. Résistance des vecteurs du paludisme vis-à-vis des pyréthrinoïdes utilisés pour l'imprégnation des moustiquaires au Bénin, Afrique de l Ouest. Bull. Soc. Pathol. Exot. 1999; 92: 123-130.

[17] Aïzoun N, Azondekon R, Akogbéto M. Establishment of the correlations between resistance level to permethrin and DDT and knocked-down time in two Anopheles gambiae sensu lato populations from the Sudano Guinean area in the central part of Benin, West Africa. Int. J. Curr. Microbiol. App. Sci. 2014; 3(10): 878-884.

[18] Coats JR. Insecticide Mode of Action. Academic Press London. 1982.

[19] Cochran DG. Effects of three synergists on Pyrethroid Resistance in the German Cockroach (Dictyoptera: Blatellidae). J. Econ. Entomol. 1994; 87(4):879-884.

[20] Aïzoun N, Azondekon R, Akogbéto M. Status of deltamethrin resistance in three Anopheles gambiae sensu lato populations from main ecological settings in Benin, West Africa. Int. J. Curr. Microbiol. App. Sci. 2014; 3(9): 5864.

[21] Aïzoun N, Azondekon R, Akogbéto M. Cyfluthrin resistance in Anopheles gambiae s.l. populations from the cotton growing area of Hlassoé in Glazoué district in the central part of Benin, West Africa. Int.J. Curr. Microbiol. App. Sci. 2014; 3(10): 899-904.

[22] Aïzoun N, Azondekon R, Akogbéto M. The L1014F kdr Mutation in Anopheles gambiae s.l. Lambdacyhalothrin Resistant Populations from Kandi District in Northern Benin, West Africa. Int. J. Curr. Res. Biosci. Plant Biol. 2014; 1(4): 9-14.

[23] Metcalf RL. A century of DDT. J. Agric. Food Chem. 1973; 21: 511-519.

[24] Magesa SM, Wilkes TJ, Mnzava AE, Njunwa KJ, Myamba J, Kivuyo MD, Hill N, Lines JD, Curtis CF. Trial of pyrethroid impregnated bednets in an area of Tanzania holoendemic for malaria. Part 2. Effects on the malaria vector population. Acta Trop. 1991; 49: 97-108.

[25] Coetzee M, Van WP, Booman M, Koekemoer LL, Hunt RH. Insecticide resistance in malaria vector mosquitoes in a gold mining town in Ghana and implications for malaria control. Bull. Soc. Pathol. Exot. 2006; 99: $400-403$.

[26] Hargreaves K, Hunt RH, Brooke BD, Mthembu J, Weeto MM, Awolola TS, Coetzee M. Anopheles arabiensis and An. quadiannulatus resistance to DDT in South Africa. Med. Vet. Entomol. 2003; 17: 417-422.

[27] Tia E, Akogbeto M, Koffi A, Toure M, Adja AM, Moussa K, Yao T, Carnevale P, Chandre F. Pyrethroid and DTT resistance of Anopheles gambiae s.s. (Diptera: Culicidae) in five agricultural ecosystems from Cote-d'Ivoire. Bull. Soc. Pathol. Exot. 2006; 99: 278-282. 